\title{
Effectiveness of Maceration Periods with Different Extraction Solvents on in-vitro Antimicrobial Activity from Fruit of Momordica charantia L.
}

\author{
Yang Lin Yeo, Yin Yin Chia, Chin Hong Lee, Heng Sheng Sow, Wai Sum Yap* \\ Department of Biotechnology, Faculty of Applied Sciences, UCSI University, Kuala Lumpur, Malaysia.
}

\begin{tabular}{|c|c|}
\hline ARTICLE INFO & ABSTRACT \\
\hline Article history: & \multirow{11}{*}{$\begin{array}{l}\text { Momordica charantia L. also known as bitter gourd, is one of the medicinal plants that have a long history usage } \\
\text { as medicine in Asia for the treatment of various ailments. The present study was aimed to evaluate the } \\
\text { effectiveness of maceration periods with various extraction solvents against four gram positive bacteria }(B \text {. } \\
\text { cereus, B. subtilis, E. faecalis and } S \text {. aureus), four gram negative bacteria (E. coli, K. pneumonia, P. aeruginosa } \\
\text { and Serratia spp.) and a fungus, } C \text {. albicans. Dried fruit powders were extracted at four maceration times }(6 \mathrm{~h} \text {, } \\
12 \mathrm{~h}, 24 \mathrm{~h} \text { and } 48 \mathrm{~h} \text { ) using different solvents (hexane, petroleum ether, ethyl acetate, acetone, ethanol and distilled } \\
\text { water). In the results, gram negative bacteria and fungus were found more susceptible as compared to gram } \\
\text { positive bacteria. Solvents with low to intermediate polarity used such as hexane, petroleum ether and ethyl } \\
\text { acetate demonstrated better antimicrobial activity as compared to other solvents used. On maceration times used, } \\
6 \mathrm{~h} \text { was found to give the best inhibition zone of the antimicrobial activity with economic feasibility, while on the } \\
\text { microorganisms tested, E. coli was found to be the most susceptible, followed by } C \text {. albicans and } K \text {. pneumonia. } \\
\text { Statistical analysis demonstrated significant difference (p < } 0.05) \text {, where maceration periods, extraction solvents } \\
\text { used as well as the type of microorganisms have significant effect on the inhibition zone. Thus, this study } \\
\text { revealed the importance of appropriate maceration periods in combination with different extraction solvents used, } \\
\text { in giving a satisfactory and reliable result on the antimicrobial activity of the nine potent microorganisms. }\end{array}$} \\
\hline Received on: 24/06/2014 & \\
\hline Revised on: $23 / 07 / 2014$ & \\
\hline Accepted on: 22/08/2014 & \\
\hline Available online: $30 / 10 / 2014$ & \\
\hline Key words: & \\
\hline Antimicrobial activity; & \\
\hline Momordica charantia L.; & \\
\hline Maceration periods; & \\
\hline Extraction solvents. & \\
\hline & \\
\hline
\end{tabular}

\section{INTRODUCTION}

Over the years, the cases of infectious disease had been elevating in an alarming rate, despite the rapid advancement in the medical field. According to Ahmad and Beg (2001), infectious diseases remain as one of the leading cause of deaths worldwide, killing about 50,000 people daily. As defined by World Health Organization (WHO), infectious diseases is an evidence disease caused by pathogenic microorganisms, such as bacteria, viruses, multicellular parasites, fungi as well as prions. The common treatment for infectious disease is with the use of antimicrobial agents such as antibiotics or chemotherapeutic drugs. Allegedly, antimicrobial drugs should only be consumed according to the appropriate dosage, as over prescription of antimicrobial drugs is a

* Corresponding Author

Wai Sum Yap, Department of Biotechnology,

Faculty of Applied Sciences, UCSI University,

Kuala Lumpur, Malaysia.Email: wsyap@ucsiuniversity.edu.my vital contributor to drug resistance (Appiah and Vlas, 2002; Marchese and Schito, 2001). In 1980s, drug resistance towards pathogens was relatively low. However, the statistic is in an alarming stage now as numerous antibiotics and drug resistance to human pathogenic cases were reported globally. Despite the breakthrough of pharmacological industries in producing new antibiotics, nonetheless there is still an elevation of resistance towards these antibiotics by microorganisms (Nascimento et al., 2000). To date, about $80 \%$ of all strains of Staphylococcus aureus were found to be resistant towards penicillin. Adding to the list, Camplylobacter spp, E. coli, Proteus spp., P. aeruginosa, S. dysenteriae, S. enteritidis, S. paratyphi, S. typhi, S. aureus, S. faecalis, and $C$. albicans are some of the example of drug resistance microorganisms (Appiah and Vlas, 2002; Barbour et al., 2004; Benzic et al., 2005). As the problem associated with microbial resistance continues to rise, yet there are still uncertainties in searching for the new antimicrobial drugs. 
Therefore, controlling the use of antibiotics, creating research and experiment for better understanding of the genetic mechanisms of resistance, as well as developing new synthetic or natural drugs are some of the effective methods taken to cope with the problem of microbial resistance (Nascimento et al., 2000). Whereby, researchers are screening and searching massively for any new antibiotics to combat the antibiotic resistance, where plant secondary metabolite still provides a mean to identify new antibiotics (Barnum, 1998). Thus, there are considerable interests in isolating, characterizing and utilizing natural antimicrobial compounds from various plant extracts in order to produce effective antimicrobial drugs (Mokbel and Hashinaga, 2005).

Nature has been a promising source of new therapeutic candidate compounds due to the tremendous chemical diversity found in various species of plants (Rocha et al., 2001). Plants are considered as a potent and powerful source of drugs that have stood the test of time, where the modern medicine and chemistry development could not replace most of them (Ahmad et al., 1998). Moreover, it has been revealed that more than $50 \%$ of all modern drugs contain natural products as the major component of modern pharmaceuticals used for the treatment of human diseases (Mayer et al., 2010; Rosangkima and Prasad, 2004). Approximately, 400 herbs have been used widely as therapeutic medicinal substances as narcotics, purgatives and sudorifics (Borzelleca, 2001; GreenHernandez et al., 2001), where morphine was first obtained from opium by Serturner in year 1806. Other compounds such as cinchonine, quinine, caffeine and brucine were successfully isolated during the next five years (Ahmed, 1994).

Phytochemicals and biological constituents in plants have remarkable contribution towards the drug industry (Srinivasan et al., 2007). The medicinal properties of plants are due to the presence of certain chemical substances which can elicit a definite physiological action in human body. The various plant parts such as roots, leaves and fruits contain bioactive compounds like alkaloidal constituents, essential oils, peptides and unsaturated long chain aldehydes, thus making them rich as a source of medicine. Moreover, Doughari et al., (2008) have indicated that these bioactive compounds are effective against human pathogens such as bacteria, fungi and viruses, which could be of great significant in therapeutic treatments.

Momordica charantia L. or bitter gourd was chosen to evaluate its antimicrobial effects in the present study due to its high utilization in traditional medicine. This plant is widely distributed throughout the tropics and used as folk remedy for various ailments which include healing of wounds, infections, measles, hepatitis and fevers (Grover and Yadav, 2004; Gủrbủz et al., 2000; Subratty et al., 2005).

The entire plant of Momordica charantia, including the fruits, seeds, leaves and stem possess medicinal values and exert therapeutic effects such as antidiabetic, antiviral, antioxidant, anticancer and anti-HIV activities (Beloin et al., 2005; Grover and Yadav, 2004; Kubola and Sirimornpun, 2008). Although numerous studies had been done on Momordica charantia L., most studies were done was for the treatment of diabetes (Han et al., 2008;
Leung et al., 2009; Singh et al., 2008), while only few studies were done on the antimicrobial activity (Braca et al., 2008; Mahmood et al., 2012), especially on fruit extract (Lu et al., 2011; Mwambete, 2009). Nonetheless, to the best of my knowledge, none of these studies revealed the importance of proper maceration periods with various extraction solvents against the inhibition activity of the microorganisms tested, which was the main aim in this study.

Therefore, this study was to assess the effectiveness of maceration periods ( $6 \mathrm{~h}, 12 \mathrm{~h}, 24 \mathrm{~h}$ and $48 \mathrm{~h}$ ) with various solvents (hexane, petroleum ether, ethyl-acetate, acetone, ethanol and distilled water) on in-vitro antimicrobial activity from fruit of Momordica Charantia L.

\section{MATERIALS AND METHODS}

\section{Plant material}

Throughout the study, the unripe fruit of Momordica charantia L. (Chinese phenotype) was supplied by a local farm located in Sitiawan, Perak, Malaysia.

\section{Preparation of plant material}

Fresh samples of Momordica charantia fruits collected were washed and the seeds were removed. The fruits were then sliced into small pieces and dried in drying oven at $50{ }^{\circ} \mathrm{C}$ until a constant weight was achieved. The dried fruits were then grounded to powder by miller with the mesh size of 813 micron (Quadro Comil, Canada) and vacuum packed until further use.

\section{Preparation of crude extracts}

$2 \mathrm{~g}$ of dry powdered plant material was extracted with $20 \mathrm{ml}$ of different solvents (hexane, petroleum ether, ethyl acetate, acetone, ethanol and distilled water) at solid to solvent ratio of $1: 10(\mathrm{w} / \mathrm{v})$ for different maceration periods $(6 \mathrm{~h}, 12 \mathrm{~h}, 24 \mathrm{~h}$ and $48 \mathrm{~h}$ ). The extraction was carried out at room temperature with agitation at $150 \mathrm{rpm}$.

\section{Filtration and solvent evaporation}

After the respective maceration periods, the soaked powder-solvent mixtures were filtered through a Whatman No. 1 filter paper, concentrated to $1 \mathrm{ml}$ with a rotary evaporator at $40-60{ }^{\circ} \mathrm{C}$ and then diluted with 5\% dimethyl sulfoxide (DMSO) at ratio $1: 1(\mathrm{v} / \mathrm{v})$. The concentrated fruit extracts were then stored at $-20{ }^{\circ} \mathrm{C}$ until further use.

\section{Test microorganisms}

In-vitro antimicrobial studies were carried out on four Gram-positive bacteria (Bacillus cereus, Bacillus subtilis, Enterococcus faecalis and Staphylococcus aureus), four Gramnegative bacteria (Escherichia coli, Klebsiella pneumonia, Pseudomonas aeruginosa and Serratia spp.) and a fungus (Candida albicans). All the microorganisms were obtained from the Laboratory of Microbiology, Faculty of Applied Sciences, UCSI University, Malaysia. 


\section{Culture media}

Nutrient agar (NA) (Himedia), nutrient broth (NB) (Merck, Germany) and potato dextrose agar (PDA) (Merck) were used during the study. NA and NB were used for the cultivation of bacteria while PDA were used to culture yeast. All bacterial cultures were incubated at $37{ }^{\circ} \mathrm{C}$ for 24 hours whereas yeast cultures were incubated at $30^{\circ} \mathrm{C}$ for 48 hours.

\section{Antimicrobial susceptibility test}

The Kirby Bauer disc diffusion method was used. The cell concentration of bacteria and yeast which were to be inoculated were standardized to $10^{6}$ to $10^{7}$ cells $/ \mathrm{mL}$ with haemacytometer (Chanwitheesuk et al., 2005). The bacterial cultures were inoculated in NB and incubated at $37{ }^{\circ} \mathrm{C}$ for $24 \mathrm{~h}$ while yeast was incubated at room temperature for $48 \mathrm{~h}$; in an orbital shaker (Infors AG, Switzerland) at 150rpm. Suspension for the respective microbes, measuring $100 \mu \mathrm{L}$ each, were pipetted and spread evenly on NA (for bacteria) and PDA (for yeast) plates, respectively with a sterilized swab. Sterilized filter paper discs (diameter, $6 \mathrm{~mm}$ ), was impregnated with $10 \mu \mathrm{L}$ of fruit extracts and allowed to be air-dried for 10 to 15 minutes. The discs were subsequently placed on the surface of inoculated agar medium. Discs with $10 \mu \mathrm{g} / \mathrm{disc}$ of ampicillin served as positive control for bacteria while $30 \mu \mathrm{g} / \mathrm{disc}$ of tetracycline were used as positive control for yeast. Different extraction solvents (hexane, petroleum ether, ethyl acetate, acetone, ethanol and distilled water) and 5\% DMSO were used as negative controls. All tests were carried out in triplicate. Zone of inhibition was then measured using a scale.

\section{Statistical analysis}

The data of inhibition zone ( $\mathrm{mm}$ ) obtained was submitted to analysis of variance using one-way Anova to detect if there is any significant difference when different variables (maceration periods, type of solvents and type of microorganisms) were used. The significances were then ranked using Tukey post-Anova analysis with $95 \%$ confidence intervals. All the tests were carried out using SPSS version 17.1.

\section{RESULTS AND DISCUSSION}

In the results obtained, a broad-spectrum of antimicrobial activity was observed using different extraction solvents in combination with different maceration periods. In Figure 1(a), where hexane was used, strong inhibition zone was observed on $C$. albicans at $6 \mathrm{~h}$ maceration period with zone inhibition of $17.8 \pm$ $0.5 \mathrm{~mm}$. Interestingly, no inhibition was observed at $12 \mathrm{~h}$ and $24 \mathrm{~h}$ for $C$. albicans, whereas a moderate inhibition with $9.3 \pm 0.3 \mathrm{~mm}$ was observed at $48 \mathrm{~h}$ maceration period. This suggests that when hexane was used, maceration period plays a very important role in determining the type and concentration of bioactive compounds extracted from the fruit of Mormodica charantia L. Hexane has a polarity index of near zero. Hence, the bioactive compounds extracted using this solvent should have similar polarity (Ncube, 2008), where the compounds responsible for the inhibition of $C$. albicans and E. coli in this study is said to be of low polarity. Similarly, in a study done by Adeloye et al., (2007) on Urena lobata Linn. leaf extract using hexane, inhibition on E. coli, C. albicans and other pathogenic microorganisms was observed where tannins were found responsible to confer the antimicrobial activity. In another study done by Hassan et al., (2006) using hexane, the leaf and root extracts of Calotropis procera were found to contain alkaloids, flavonoids, tannins, steroids, triterpenoids, saponins and saponin glycosides which were postulated to be responsible for the inhibition of Trichophyton rubrum, Microsporum gypseum and Aspergillus niger. On the other hand, when petroleum ether was used [as shown in Figure 1(b)], E. coli was shown to be the most susceptible towards the inhibition with $22.3 \pm 0.4 \mathrm{~mm}$ at $48 \mathrm{~h}$ maceration, followed by $C$. albicans with $10.3 \pm 0.7 \mathrm{~mm}$ at $6 \mathrm{~h}$ maceration, while low or no inhibition was observed for all other microorganisms. E. coli was also found to be susceptible towards hexane extract [Figure 1(a)] at $48 \mathrm{~h}$ maceration with inhibition zone of $12.0 \pm 0.5 \mathrm{~mm}$. Thus, it can be postulated that the antimicrobial compounds which are responsible for $E$. coli inhibition, tend to be extracted at longer maceration time with lower polarity index solvent such as hexane. In this study, when hexane or petroleum ether was used, the antimicrobial compounds present possess better inhibition towards $C$. albicans with $6 \mathrm{~h}$ maceration while for $E$. coli, longer maceration period ( $48 \mathrm{~h}$ ) was needed. Therefore, it is proposed that the antifungal agents responsible to inhibit the growth of $C$. albicans were unstable and might be decomposed, when longer maceration period was imposed (Chan et al., 2009). Moreover, according to Trusheva et al., (2007), longer maceration time would lead to chemical changes, particularly oxidation of phenolic compounds such as flavonoids. This might be the reason why no antifungal activity was observed for hexane macerated at $12 \mathrm{~h}$ and $24 \mathrm{~h}$, respectively while mild antifungal activity $(9.3 \pm 0.3 \mathrm{~mm})$ was observed at $48 \mathrm{~h}$ maceration might be due to the presence of other phytochemicals that conferred the activity. Contrarily, in $E$. coli, the antibacterial agents were relatively potent at $48 \mathrm{~h}$ maceration, indicating that maceration period of lesser than $48 \mathrm{~h}$ might not be sufficient to exhibit the antimicrobial activity and longer period was needed to increase the yield of the extracted material (da Silva Cunha et al., 2006). As for ethyl-acetate [Figure 1(c)], similarly, E. coli was also found to be the most susceptible towards the inhibition at both $12 \mathrm{~h}$ and $24 \mathrm{~h}$ maceration periods with $12.7 \pm 1.5 \mathrm{~mm}$ and $12.0 \pm 1.2 \mathrm{~mm}$, respectively. Only moderate inhibition could be observed on $P$. aeruginosa macerated at $24 \mathrm{~h}$ with $10.3 \pm 0.5 \mathrm{~mm}$ while low inhibition was found in $C$. albicans with $8.0 \pm 0.2 \mathrm{~mm}$ at $24 \mathrm{~h}$ maceration. Other microorganisms showed low or no inhibition. Ethyl-acetate has been widely used as an extraction solvent for numerous antimicrobial studies conducted. In a study conducted by Adeshina et al., (2010) on leaf of Alchornea cordifolia using hexane, ethylacetate and methanol as extraction solvents, ethyl-acetate shown to be the best solvent used that conferred the antimicrobial activity against $P$. aeruginosa, S. aureus, E. coli and $C$. albicans with diameter of inhibition zone ranging from $10.0-35.0 \mathrm{~mm}$. 


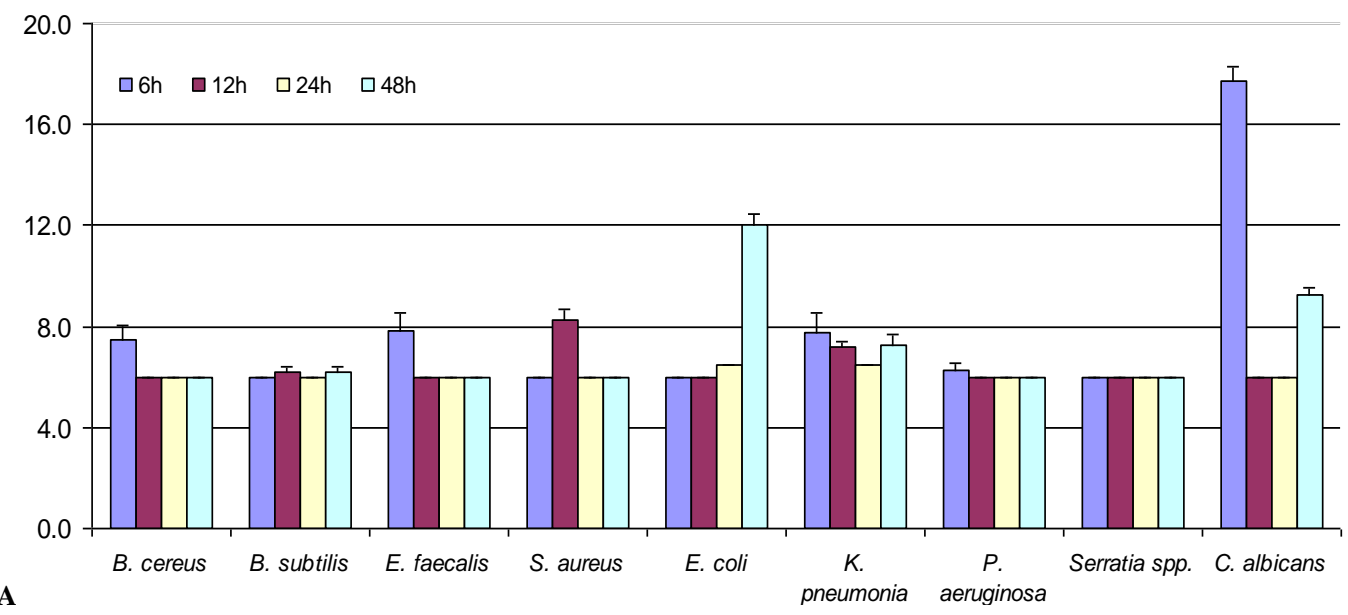

Fig. A

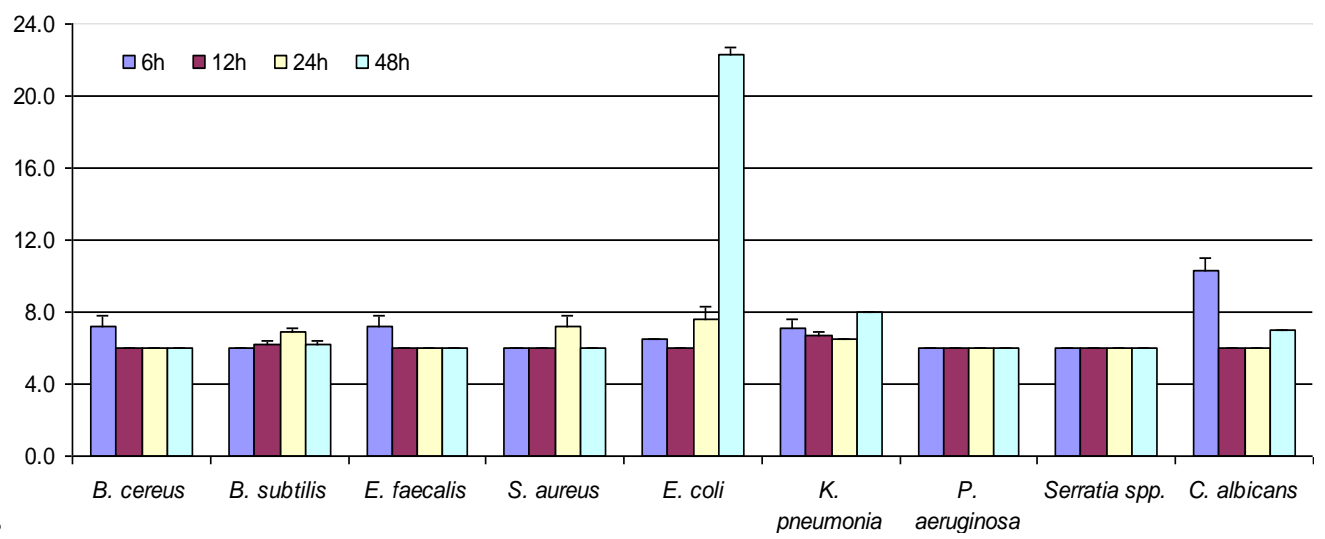

Fig. B

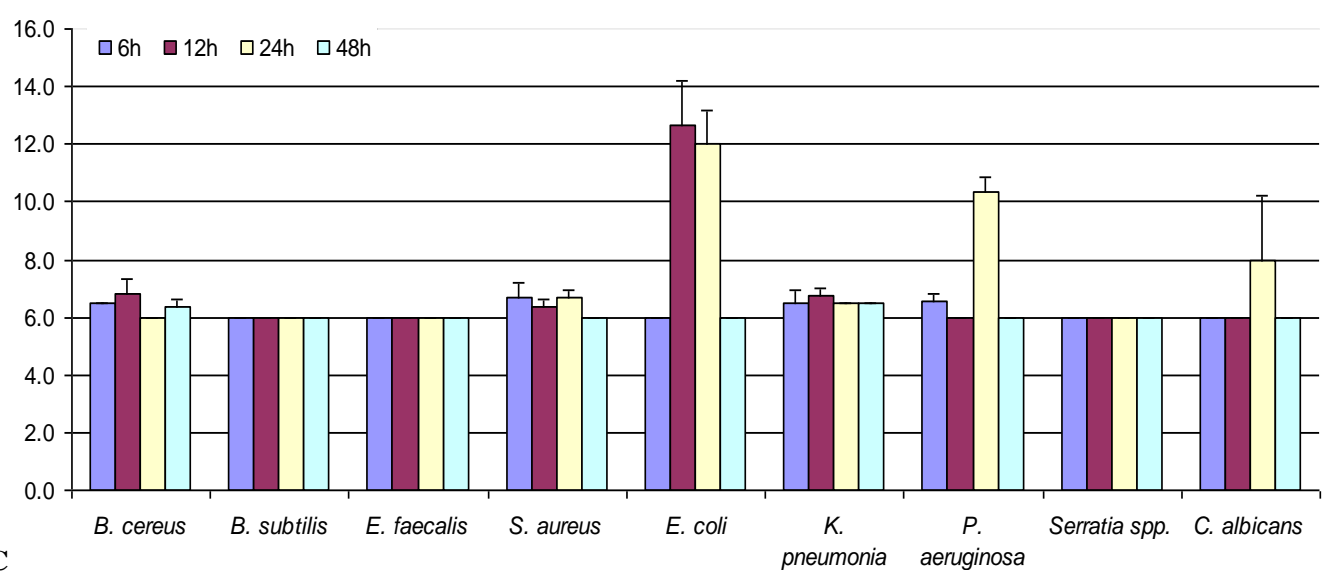

Fig. C

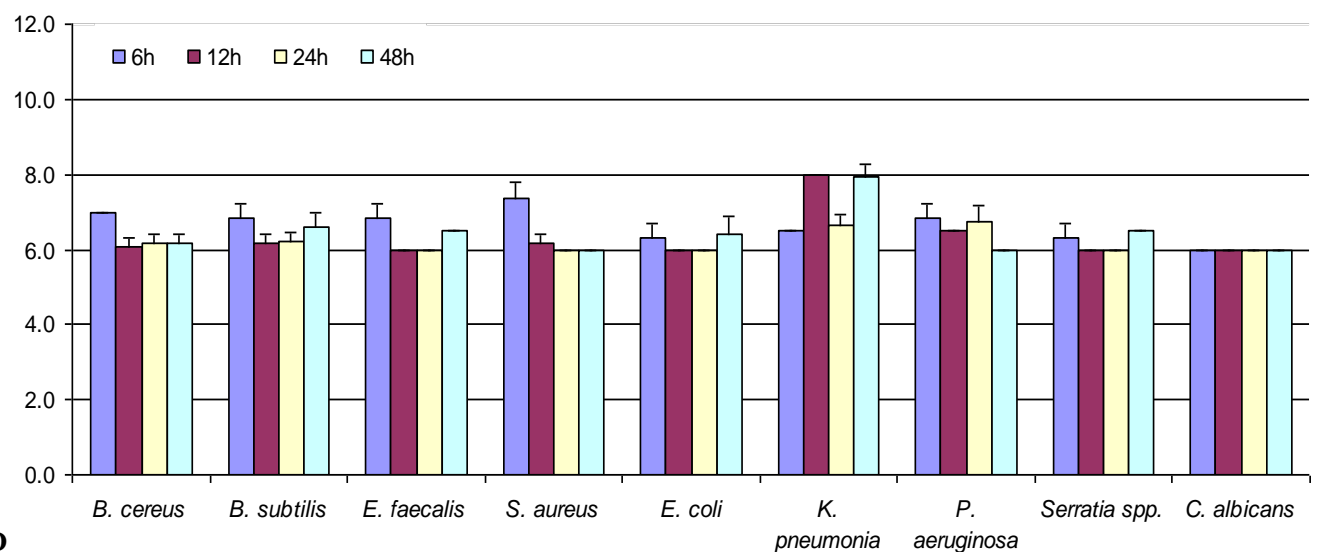




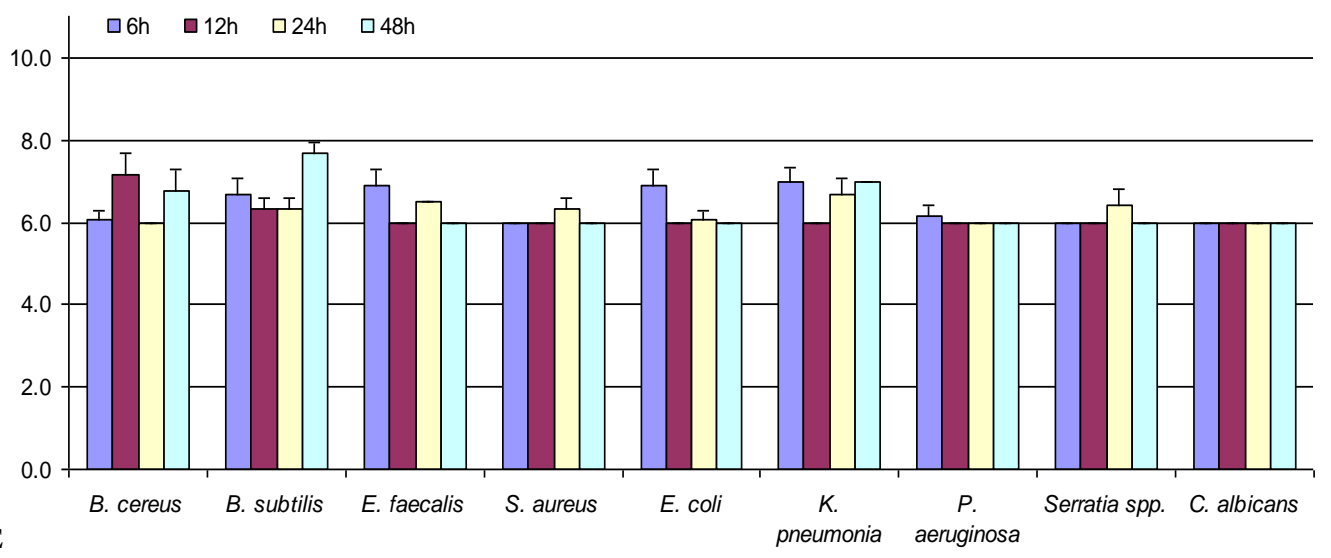

Fig. E

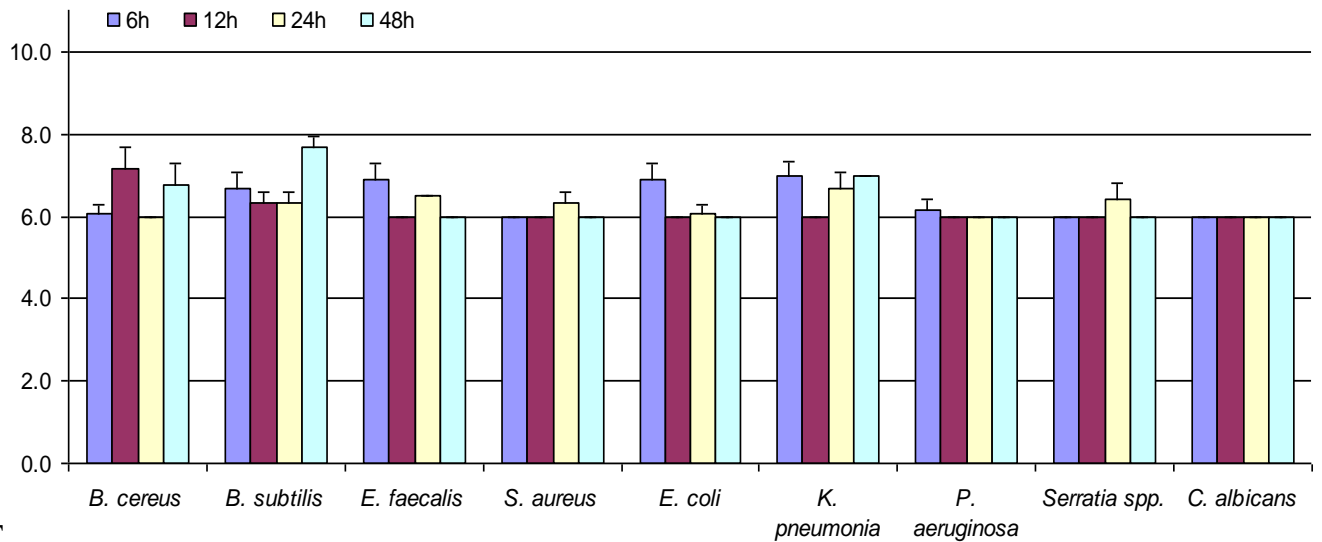

Fig. F

Fig. 1: Antimicrobial activity (disc diffusion method zone of inhibition in $\mathrm{mm}$ ) of Momordica charantia $\mathrm{L}$. fruit using four maceration periods $(6 \mathrm{~h}, 12 \mathrm{~h}, 24 \mathrm{~h}$ and 48 h) with different extraction solvents. (A) Hexane; (B) Petroleum ether; (C) Ethyl acetate; (D) Acetone; (E) Ethanol and (F) Distilled water.

The phytochemical screening of this plant revealed the presence of tannins, flavonoids, glycoside, resins and carbohydrates. In another study conducted by Gangadevi et al., (2008) on the antimicrobial activity of Acalypha indica L. in leaf, stem and root using 3 different solvents (hexane, ethyl-acetate and methanol), greater zone of inhibition was found in ethyl-acetate extract against $B$. subtilis, $K$. pneumonia and S.aureus, thus indicating that the active ingredients in this plant are more readily dissolved or extracted in ethyl-acetate compared with other solvents used.

On the other hand, when more polar solvents such as acetone, ethanol and distilled water [Figure 1(d), 1(e) and 1(f)] were used as extraction solvents, only low inhibition (range from $8.0 \pm 0.0 \mathrm{~mm}$ to $6.17 \pm 0.3 \mathrm{~mm}$ ) was observed in some of the microorganisms tested. Using acetone, K. pneumonia was found to be inhibited by all different maceration periods used while in $P$. aeruginosa, only extracts macerated at $6 \mathrm{~h}, 12 \mathrm{~h}$ and $24 \mathrm{~h}$ could inhibit the growth of this microbe, but not $48 \mathrm{~h}$. For ethanol extract, B. subtilis was inhibited by four different maceration periods used, but with only low inhibition, ranging from $7.7 \pm 0.3 \mathrm{~mm}$ to $6.3 \pm$ $0.3 \mathrm{~mm}$. Distilled water extract on the other hand, showed the poorest of all solvents used where it could not inhibit most of the microorganisms tested. Only E. faecalis, E. coli and C. albicans showed low inhibition at $6 \mathrm{~h}$ maceration period. Thus, the finding from this study showed that non-polar and intermediate-polar solvents (hexane, petroleum ether and ethyl-acetate) were better solvent systems used in extracting antimicrobial compounds from fruit of Momordica charantia L. In a study done by Keskin and Toroglu (2001) on antimicrobial activities of different solvent extracts (methanol, acetone and ethyl-acetate) using different spices, their results revealed that none singular extraction solvent was effective against all microbes tested in any of the plant spices. Thus, the study concluded that there are differences in the antimicrobial effects of plant groups due to the phytochemical differences between species as well as the collection site (Keskin and Toroglu, 2001).

Nevertheless, the study conducted in this paper revealed that even in a singular plant (bitter gourd), when different extraction solvent was used, there were differences on the antimicrobial effects towards the microorganisms tested.

This is further confirmed when statistical analysis oneway ANOVA (Table 1) revealed that the inhibition zone $(\mathrm{mm})$ depends on the type of extraction solvents, maceration periods as well as the strain of microorganisms used, was statistically significant where $p<0.05$. In determining the best extraction solvents, further analysis with Tukey's multiple comparison tests revealed that hexane, petroleum ether and ethyl-acetate (Table 2) demonstrated better antimicrobial activity as compared to other solvents used. Thus, the results revealed that the active anti- 
microbial compounds from fruit of bitter gourd are mostly in the categories of non-polar to intermediate polarity.

Table 1: Statistical analysis using One-way ANOVA on different parameters towards the inhibition zone $(\mathrm{mm})$ of microorganisms tested.

\begin{tabular}{lll}
\hline & Variable & P-value \\
\hline \multirow{3}{*}{ Inhibition zone $(\mathrm{mm})$} & Type of solvents & $<0.05^{*}$ \\
& Maceration periods & $<0.05^{*}$ \\
& Type of microorganisms & $<0.05^{*}$ \\
\hline
\end{tabular}

* $\mathrm{P}<0.05$ denoted statistically significant.

Table 2: Effect of extraction solvents on the inhibition zone (mm). Results were obtained from the nine microorganisms tested at four different maceration periods, with mean $\pm \mathrm{SD}$, where $\mathrm{n}=108$.

\begin{tabular}{cc}
\hline Extraction Solvent & Inhibition Zone (mm) \\
\hline Hexane & $6.90 \pm 2.22^{\mathrm{a}}$ \\
Petroleum ether & $6.92 \pm 2.22^{\mathrm{a}}$ \\
Ethyl acetate & $6.70 \pm 1.60^{\mathrm{a}, \mathrm{b}}$ \\
Acetone & $6.41 \pm 0.52^{\mathrm{b}, \mathrm{c}}$ \\
Ethanol & $6.31 \pm 0.44^{\mathrm{b}, \mathrm{c}}$ \\
Distilled water & $6.08 \pm 0.25^{\mathrm{c}}$ \\
\hline Different superscripts denoted statistical significance, with P $<0.05$.
\end{tabular}

Table 3: Effect of different types of microorganisms on the inhibition zone $(\mathrm{mm})$. Results were obtained from six extraction solvents used at four different maceration periods, with mean $\pm S D$, where $n=72$.

\begin{tabular}{lc}
\hline \multicolumn{1}{c}{ Type of Microorganism } & \multicolumn{1}{c}{ Inhibition Zone $(\mathbf{m m})$} \\
\hline Gram postive bacteria: & $6.33 \pm 0.48^{\mathrm{c}, \mathrm{d}}$ \\
B. cereus & $6.26 \pm 0.41^{\mathrm{c,d}}$ \\
B. subtilis & $6.28 \pm 0.51^{\mathrm{c}, \mathrm{d}}$ \\
E. faecalis & $6.29 \pm 0.58^{\mathrm{c,d}}$ \\
S. aureus & \\
Gram negative bacteria: & $7.68 \pm 3.73^{\mathrm{a}}$ \\
\hline E. coli & $6.80 \pm 0.63^{\mathrm{b}}$ \\
K. pneumonia & $6.31 \pm 0.89^{\mathrm{c}, \mathrm{d}}$ \\
P. aeruginosa & $6.05 \pm 0.14^{\mathrm{d}}$ \\
Serratia spp. & \\
Fungus: & $6.96 \pm 2.56^{\mathrm{b}}$ \\
\hline C. albicans & \\
\hline
\end{tabular}

* Different superscripts denoted statistical significance, with $\mathrm{P}<0.05$.

On the other hand, on microbial susceptibility, analysis with Tukey's multiple comparison tests (Table 3) demonstrated that $E$. coli was the most susceptible microbe, followed by $C$. albicans and K. pneumonia.

In majority of the antimicrobial study conducted by other researchers, most of the antimicrobial agents obtained from plant extracts were more potent towards gram positive bacteria (Chia and Yap, 2011; Kaneria et al., 2009; Rahman et al., 2011; Somchit et al., 2010; Srinivas et al., 2010) while the results of this paper revealed the potency of Momordica charantia L. fruit extracts towards gram negative bacteria ( $E$. coli and K.pneumonia) and fungi (C. albicans). The result from this finding is more prominent when the positive controls used in this study (ampicillin $10 \mathrm{ug} / \mathrm{disc}$ for bacteria and tetracycline - 30ug/disc for fungi in Table 5) were unable to inhibit $K$. pneumonia, while only low inhibition zone was demonstrated in both E. coli and C. albicans. Moreover, E. coli is well known for its multi-resistance towards drug (Sjölund et al., 2008).

On the differences of maceration times toward the antimicrobial compounds extracted, it is notable that an increased in maceration period could improve the bioactive compounds extracted, where Zoecklein (2006) revealed that an increased contents of anthocyanin and tannin were found in wine,when longer maceration time was used. Subsequently, in a study done by Turkmen et al., (2007) on antimicrobial activity of black tea using different extraction solvents, increasing of maceration time from $2 \mathrm{~h}$ to $18 \mathrm{~h}$ significantly increased the antibacterial activity of the extract, depending upon the microorganism tested as well as the solvents used.

In contrast to this study, the best maceration times found were $6 \mathrm{~h}$ and $48 \mathrm{~h}$ (no significance different) when Tukey's multiple comparisons test was imposed (Table 4). On maceration time, in a research done by da Silva Cunha et al., (2006), the prolonged extraction periods did not enhance richer propolis extracts was found, nevertheless a decreased in the activity was observed.

Table 4: Effect of different maceration periods on the inhibition zone (mm). Results were obtained from nine microorganisms tested using six different extraction solvents, with mean $\pm \mathrm{SD}$, where $\mathrm{n}=162$.

\begin{tabular}{cc}
\hline Maceration Time & Inhibition Zone $(\mathbf{m m})$ \\
\hline $6 \mathrm{~h}$ & $6.74 \pm 1.70^{\mathrm{a}}$ \\
$12 \mathrm{~h}$ & $6.33 \pm 1.00^{\mathrm{b}}$ \\
$24 \mathrm{~h}$ & $6.42 \pm 1.04^{\mathrm{a}, \mathrm{b}}$ \\
$48 \mathrm{~h}$ & $6.71 \pm 2.39^{\mathrm{a}}$ \\
\hline
\end{tabular}

* Different superscripts denoted statistical significance, with $\mathrm{P}<0.05$.

Table 5: Positive controls. Ampicillin (10ug/disc) was used for both gram positive and gram negative bacteria, while tetracycline (30ug/disc) was used for fungi. Results were mean $\pm \mathrm{SD}$, where $\mathrm{n}=3$.

\begin{tabular}{lc}
\hline \multicolumn{1}{c}{ Type of Microorganism } & Inhibition Zone (mm) \\
\hline Ampicillin (10ug/disc) & \\
Gram postive bacteria: & $8.11 \pm 0.23$ \\
\hline B. cereus & $8.30 \pm 0.07$ \\
B. subtilis & $14.54 \pm 0.79$ \\
E. faecalis & $23.30 \pm 1.11$ \\
S. aureus & $6.27 \pm 0.01$ \\
Gram negative bacteria: & $6.00 \pm 0.00$ \\
\hline E. coli & $18.17 \pm 0.24$ \\
K. pneumonia & $6.28 \pm 0.10$ \\
P. aeruginosa & \\
Serratia spp. & \\
Tetracycline (30ug / disc) & $9.53 \pm 0.09$ \\
Fungus: & \\
\hline C. albicans & \\
\hline
\end{tabular}

\section{CONCLUSIONS}

This study revealed that maceration periods and type of extraction solvents are significantly influenced the inhibition zone $(\mathrm{mm})$ of the nine potent microorganisms tested. Therefore, it is of great important to use an optimum maceration period in combination with suitable extraction solvents in order to obtain the desirable antimicrobial compounds from fruit of Momordica chrantia L. against the microorganisms tested.

\section{ACKNOWLEDGEMENT}

This research was funded by CERVIE, UCSI University Internal Grant, Proj-in-FAS 001. 


\section{REFERENCES}

Adeloye OA, Akinpelu AD, Ogundaini OA and Obafemi C. Studies on antimicrobial, antioxidant and phytochemical analysis of Urenalobata leave extract. J Phys Nat Sci, 2007; 1(2): 1-9.

Adeshina GO, Onaolapo JA, Ehinmidu JO and Odama LE. Phytochemical and antimicrobial studies of the ethyl acetate extract of Alchornea cordifolia leaf found in Abuja. Nigeria J Med Plants Res, 2010; 4: 649-658.

Ahmad I and Beg AZ. Antimicrobial and phytochemical studies on 45 Indian medicinal plants against multi-drug resistant human pathogen. J Ethnopharmacol, 2001; 74: 113-123.

Ahmad I, Mehmood Z and Mohammad F. Screening of some Indian medicinal plants for their antimicrobial properties. J Ethnopharmacol, 1998; 62: 183-193.

Ahmed M. Synthesis of some nicotinic acid derivatives as potential therapeutic agents and extraction, isolation of active components of Momordica charantia. PhD Thesis. University of Karachi 1994, Pakistan.

Appiah DAS and Vlas TDC. Interpretation of low praziquantel cure rates of Schistosoma mansoni. Trends Parasitol, 2002;18: 95-143.

Barbour EK, Al-Sharif M, Sagherian VK, Habre AN, Talhouk RS and Talhouk SN. Screening of selected indigenous plants of Lebanon for antimicrobial acitivity. J Ethnopharmacol, 2004;93: 17.

Barnum SR. 1998. Biotechnology: An Introduction. USA: Wadsworth Publishing Company.

Beloin N, Gbeassor M, Akpagana K, Hudson J, Soussa K, Koumaglo K and Arnason JT. Ethnomedicinal uses of Momordica charantia (Cucurbitaceae) in Togo and relation to its phytochemistry and biological activity. J Ethnopharmacol, 2005; 96: 49-55.

Bezic N, Skocibusic M and Dunkic V. Phytochemical composition and antimicrobial activity of Satureja montanaL. and Satureja cuneifolia Ten. essential oils. Acta Bot Croat, 2005; 64(2): 13-322.

Borzelleca JF. 2001. The art, the science, and the seduction of toxicology: An evolutionary development. In: Hayes, AW, ed. Principles and methods of toxicology, $4^{\text {th }}$ ed. New York: CRC Press, pp8.

Braca A, Siciliano T, D'Arrigo, M and Paola Germanò, M. Chemical composition and antimicrobial activity of Momordica charantia seed essential oil. Fitoterapia, 2008; 79: 123-125.

Chan SW, Lee CY, Yap CF, Wan Aida WM and Ho CW. Optimisation of extraction conditions for phenolic compounds from limau purut (Citrus hystrix) peels. Int Food Res J, 2009; 16: 203-213.

Chanwitheesuk A, Teerawutgulrag A, Kilburn JD and Rakariyatham N. Antimicrobial Gallic Acid from Caesalpinia mimosoides. J Food Chem, 2005; 100: 1044-1048.

Chia YY and Yap WS. In vitro antimicrobial activity of hexane: petroleum ether extracts from fruits of Momordica charantia L. Int J Pharm \& Biol Arch, 2011; 2(3): 868-873.

da Silva Cunha IB, Rodrigues MLT, Meurer EC, Bankova VS, Marcucci MC, Eberlin MN and Sawaya ACHF. Effect of the maceration time on chemical composition of extracts of Brazilian propolis. J Apicultural Res, 2006; 45(3): 137-144.

Doughari JH, El-Mahmood AM and Tyoyina I. Antimicrobial activity of leaf extracts of Senna obtusifolia (L). Afr J Pharm Pharmacol, 2008; 2 (1): 7-13.

Gangadevi V, Yogeswari S, Kamalraj S, Rani G and Muthumary J. The antibacterial activity of Acalypha indica L. Ind J Sci Tech, 2008; 1: 1-5.

Green-Hernandez C, Singleton JK and Aronzon DZ, 2001. Primary care pediatrics. USA: Lippincott Williams and Wilkins, pp29.
Grover JK and Yadav SP. Pharmacological actions and potential uses of Momordica charantia: a review. J Ethnopharmacol, 2004; 93: 123-132.

Gủrbủz I, Akyuz C, Yesilada E and Sener B. Anti ulcerogenic effect of Momordica charantia L. fruit on various ulcer models in rats, J Ethnopharmacol, 2000; 71 : 77-82.

Han C, Hui Q and Wang Y. Hypoglycaemic activity of saponin fraction extracted from Momordica charantia in PEG/salt aqueous two-phase systems. Nat Prod Res, 2008; 22: 1112-1119.

Hassan SW, Bilbis FL, Ladan MJ, Umar RA, Dangoggo SM, Saidu Y, Abubakar MK and Faruk UZ. Evaluation of antifungal activity and phytochemical analysis of leaves, roots and stem bark extracts of Calotropis procera (Asclepiadaceae). Pakistan J Biol Sci, 2006; 9: 2624-2629.

Kaneria M, Baravalia Y, Vaghasiya Y and Chanda S. Determination of antibacterial and antioxidant potential of some medicinal plants from Saurashtra region India. Indian J Pharm Sci, 2009; 71: 406-12.

Keskin D and Toroglu S. Studies on antimicrobial activities of solvent extracts of different spices. J Environ Biol, 2001; 32(2): 251-256.

Kubola $\mathbf{J}$ and Sirimornpun S. Phenolic contents and antioxidant activities of bitter gourd (Momordica charantia L.) leaf, stem, fruit fraction extracts in vitro. Food Chem, 2008; 110: 881-890.

Leung L, Birtwhistle R, Kotecha J, Hannah S and Cuthbertson S. Anti-diabetic and hypoglycaemic effects of Momordica charantia (bitter melon): a mini review. Brit J Nutr, 2009; 102: 1703-1708.

Lu YL, Liu YH, Liang WL, Chyuan JH, Cheng KT, Liang $\mathrm{HJ}$ and Hou WW. Antibacterial and cytotoxic activities of different wild bitter gourd cultivars (Momordica charantia L. var. abbreviata Seringe). Bot Stud, 2011; 52: 427-434.

Mahmood A, Kaukab RG, Mahmood T, Gulfraz M and Khanum A. Isolation and characterization of antimicrobial activity conferring component(s) from seeds of bitter gourd (Momordica charantia). J Med Plants Res, 2012; 6(4): 566-573.

Marchese A and Schito GC. Role of global surveillance in combating bacterial resistance. Drugs, 2001; 61: 1671-1673.

Mayer AMS, Glaser KB, Cuevas C, Jacobs RS, Kem W, Little RD, McIntosh JM, Newman DJ, Potts BC and Shuster DE. The odyssey of marine pharmaceuticals: a current pipeline perspective. Trends Pharmacol Sci, 2010; 31(6): 255-265.

Mokbel MS and Hashinaga F. Antibacterial and antioxidant activities of banana (Musa, AAA cv. Cavendish) fruits peel. Am J Biochem Biotechnol, 2005; 1 (3): 125-131.

Mwambete KD. The in vitro antimicrobial activity of fruit and leaf crude extracts of Momordica charantia: A Tanzania medicinal plant. Afr Health Sci, 2009;9(1): 34-39.

Nascimento GGF, Locatelli J, Freitas PC and Silva GL. Antibacterial activity of plant extracts and phytochemical on antibiotic resistant bacteria. Braz J Microbiol, 2000; 31: 247-256.

Ncube NS, Afolayan AJ and Okohs AL. Assessment techniques of antimicrobial properties of natural compounds of plant origin: Current methods and future trends. Afr J Biotechnol, 2008; 7: 1797-1806.

Rahman MA, Haque E, Hasanuzzaman M and Shahid IZ. Antinociceptive, antiinflammatory and antibacterial properties of Tamarix indica roots. Int J Pharmacol, 2011; 7: 527-531.

Rocha AB, Lopes RM and Schwartsmann G. Natural products in anticancer therapy. Curr Opin Pharmacol, 2001; 1: $364-$ 369.

Rosangkima G and Prasad SB. Antitumour activity of some plants from Meghalaya and Mizoram against murine ascites Dalton's lymphoma. Indian J Exp Biol, 2004; 42: 981-988. 
Singh N, Gupta M, Sirohi P and Varsha. Effects of alcoholic extract of Momordica charantia(Linn.) whole fruit powder on the pancreatic islets of alloxan diabetic albino rats. J Exp Bot, 2008; 29: 101-106.

Sjölund M, Bonnedahl J, Hernandez J, Bengtsson S, Cederbrant G, Pinhassi J, Kahlmeter G and Olsen B. Dissemination of multidrug-resistant bacteria into the Arctic. Emerg Infect Dis, 2008;14: 70-72.

Somchit MN, Abdul RR, Abdullah A, Zuraini A, Zakaria AZ, Sulaiman MR, Arifah AK and Mutalib AR. In vitro antimicrobial activity of leaves of Acalyphaindica Linn. (Euphorbiaceae). Afr J Micro Res, 2010; 4(20): 2133-2136.

Srinivasan K, Natarajan D, Mohanasundari C, Venkatakrishnan C and Nagamurugan N. Antibacterial, preliminary phytochemical and pharmacognostical screening on the leaves of Vicoa indica (L.) DC. Iran J Pharm Ther, 2007; 6: 109-113.

Srinivas N, Jetter P, Ueberbacher BJ, Werneburg M, Zerbe K, Steinmann J, Van der Meijden B, Bernardini F, Lederer A, Dias RLA, Misson PE, Henze H, Zumbrunn J, Gombert FO, Obrecht D, Hunziker P, Schauer S, Ziegler U, Kach A, Eberl L, Riedel K, De Marco

SJ and Robinson JA. Peptidomimetic antibiotics target outermembrane biogenesis in Pseudomonas aeruginosa. Science, 2010;327: $1010-1013$.

Subratty AH, Fakim AG and Mahomoodally F. Bitter melon: an exotic vegetable with medicinal values. Nutrition and Food Science, 2005; 35(3): 143-147.
Trusheva B, Trunkova D and Bankova V.Different extraction methods of biologically active components from propolis: a preliminary study. Chem Cen J, 2007; 1: 13.

Turkmen N, Velioglu YS, Sari F and Polat G. Effect of extraction conditions on measured total polyphenol contents and antioxidant and antibacterial activities of black tea. Molecules, 2007; 12: 484-496.

Zoecklein B, 2006. Tannins, color and the 2006 season, continued: phenolic compounds and red wine processing.Enology Notes $\quad$ [117. [ONLINE] Available at: http://www.apps.fst.vt.edu/extension/enology/EN/117.html. [Accessed 10 September 2011]

\section{How to cite this article:}

Yang Lin Yeo, Yin Yin Chia, Chin Hong Lee, Heng Sheng Sow, Wai Sum Yap. Effectiveness of Maceration Periods with Different Extraction Solvents on in-vitro Antimicrobial Activity from Fruit of Momordica charantia L. J App Pharm Sci, 2014; 4 (10): 016-023. 